\title{
IN SITU RIGHT INTERNAL THORACIC ARTERY GRAFT VIA TRANSVERSE SINUS FOR REVASCULARIZATION OF POSTEROLATERAL WALL: EARLY RESULTS IN 116 CASES
}

Koji Ueyama, MD

Ryuzo Sakata, MD

Yusuke Umebayashi, MD

Yoshihiro Nakayama, MD

Katsuya Arakaki, MD

Masashi Ura, MD
The in situ right internal thoracic artery graft brought through the transverse sinus was used to revascularize the posterolateral wall in $\mathbf{1 1 6}$ patients. Its advantages were assessed retrospectively. The graft was anastomosed to the circumflex marginal branch in 70 patients $(60 \%)$ or to the posterolateral branch in 41 patients (35\%). One patient died (mortality rate $0.9 \%$ ). Perioperative myocardial infarction occurred outside the territory of the right internal thoracic artery graft in 10 patients, four of whom required mechanical support for hemodynamic deterioration. Postoperative early angiography in 114 patients found the graft to be patent in $\mathbf{9 7 . 4 \%}$. The ratio of the diameter of the right internal thoracic artery to that of the recipient marginal branch was $0.94 \pm 0.18(n=69)$, and that to the posterolateral branch was $0.88 \pm 0.18(n=37)$ (not significantly different). Results of a postoperative stress test were abnormal in one patient (1/96 tested patients). This retrospective study suggests that the right internal thoracic artery brought through the transverse sinus to revascularize the posterolateral wall provided excellent early patency and good clinical results, even to the most distally located branches. This continues to be our procedure of choice for patients with multivessel coronary disease. (J Thorac Cardiovasc Surg 1996;112:731-6)
$T^{\mathrm{h}}$ he long-term patency rate of internal thoracic artery (ITA) grafts has been far superior to that of saphenous vein grafts. ${ }^{1-5}$ At present the ITA is considered the conduit of first choice for coronary artery bypass grafting (CABG), and double ITA grafts were expected to improve survival. ${ }^{6-12}$ However, on long-term follow-up only better clinical benefits were noted. The study, however, included a high early mortality. ${ }^{13}$ In an effort to further expand the use of arterial grafts, free ITA grafts ${ }^{14-16}$ or sequential ITA grafts ${ }^{14,17,18}$ have been advocated. The need for an aortic anastomosis in free grafts necessarily adds a potential site of occlusion, as reflected by the $77 \%$ patency rate reported by the Cleveland Clinic group. ${ }^{16}$ In our institution, when both ITA grafts are used for coronary revasculariza-

From the Department of Cardiovascular Surgery, Kumamoto Central Hospital, Kumamoto, Japan.

Received for publication Oct. 25, 1995; revisions requested Dec. 4, 1995; revisions received Jan. 2, 1996; accepted for publication March 4, 1996.

Address for reprints: Ryuzo Sakata, MD, Department of Cardiovascular Surgery, Kumamoto Central Hospital, 1-16-1 Shinyashiki, Kumamoto 862, Japan.

Copyright (C) 1996 by Mosby-Year Book, Inc.

$0022-5223 / 96 \$ 5.00+0 \quad \mathbf{1 2 / 1 / 7 3 2 3 9}$ tion the right ITA is brought through the transverse sinus for grafting the circumflex area, as described by Puig and associates ${ }^{19}$ and the left ITA is anastomosed to the left anterior descending (LAD) coronary artery. Bringing the right ITA through the transverse sinus for grafting has been controversial ever since its original description by Puig's group. To further evaluate the method, we analyzed retrospectively the early postoperative angiograms, the stress tests, and the morbidity and mortality.

\section{Patients and methods}

Patient population. In 23\% (116 patients) of all patients undergoing isolated CABG from September 1989 to December 1994, we used the in situ right ITA via the transverse sinus for revascularization of the posterolateral wall of the left ventricle. The preoperative characteristics of the patients are shown in Table I. Hypertension was defined as a diastolic pressure greater than $90 \mathrm{~mm} \mathrm{Hg}$ or as the need for antihypertensive medication. Diabetes was considered present if patients were receiving insulin or oral hypoglycemic agents or had been placed on calorierestricted diets by a physician. Hyperlipidemia was considered present in patients whose serum cholesterol level was greater than $260 \mathrm{mg} / \mathrm{dl}$, or whose serum triglyceride level was greater than $200 \mathrm{mg} / \mathrm{dl}$, or who were being treated with oral medication. Left main trunk disease was defined as greater than $50 \%$ stenosis of the left main 
Table I. Clinical profile

$\begin{array}{lc}\text { Mean age (yr) } & 62.6(13-77) \\ \text { Male/female } & 95: 21 \\ \text { No. of vessels diseased } & \\ \text { Left main trunk } & 38(33 \%) \\ \text { One vessel } & 0 \\ \text { Two vessels } & 24(21 \%) \\ \text { Three vessels (without left main trunk) } & 54(47 \%) \\ \text { Risk factors } & \\ \text { Hypertension } & 60(52 \%) \\ \text { Diabetes mellitus } & 28(24 \%) \\ \text { Hyperlipidemia } & 39(34 \%) \\ \text { Previous myocardial infarction } & 68(59 \%) \\ \text { Previous cerebral vascular accident } & 8(7 \%)\end{array}$

Table II. Operative data

$\begin{array}{lc}\text { Mean No. of distal anastomoses } & 3.4 \pm 0.9 \\ \text { Mean No. of arterial graft anastomoses } & 2.1 \pm 0.4 \\ \text { ECC time (min) } & 144 \pm 38 \\ \text { Asc. Ao clamp time (min) } & 94 \pm 29 \\ \text { RITA + vein } & 3 \\ \text { RITA + LITA } & 20 \\ \text { RITA + LITA + vein } & 90 \\ \text { RITA + LITA + RGEA } & 1 \\ \text { RITA + LITA + RGEA + vein } & 2\end{array}$

ECC, Extracorporeal circulation; $A s c$ Ao, ascending aorta; RITA, right internal thoracic artery; $L I T A$, left internal thoracic artery; $R G E A$, right gastroepiploic artery.

trunk. Fourteen of those had branch vessel disease as well. Two patients had sequelae of cerebrovascular disease, one having left hemiplegia and the other right hemiplegia.

Operative data. The combinations of graft conduits and other operative data are illustrated in Table II. Both ITAs were harvested in all patients; the left ITA could not be used in two because of injury at the time of harvesting, and in another patient the left ITA was lacerated after the patient had been weaned from cardiopulmonary bypass, and the arterial graft had to be replaced with a venous graft. Therefore 113 patients $(97 \%)$ ultimately had bilateral ITA grafts. In addition to bilateral ITA grafting, three patients received a right gastroepiploic artery graft. Overall, revascularization was accomplished with only arterial grafts in 21 patients.

The target vessels for the left ITA and right ITA grafts are shown in Table III. The left ITA was anastomosed to the LAD system in 109 cases (96\%). Sequential ITA grafting was used for the diagonal branch-LAD combination in 11 patients; two left ITA conduits were used as free grafts. The right ITA via the transverse sinus was grafted to the marginal branch in 70 patients $(60 \%)$ and to the posterolateral branch in 41 patients $(35 \%)$. No right coronary artery branch was revascularized with the ITA.

Operative technique. Both ITAs were harvested with the use of low-current electrocoagulation and metallic clips (Ethicon, Inc., Somerville, N.J.), with both pleural cavities being opened. The ITA pedicle was mobilized with $2 \mathrm{~cm}$ wide margins from the point $2 \mathrm{~cm}$ distal to its bifurcation into the superficial epigastric and musculo-
Table III. Target vessels of ITA grafts

\begin{tabular}{lc}
\hline & No. of grafts \\
\hline RITA grafts via transverse sinus & \\
Circumflex system & \\
$\quad$ Marginal branch & 70 \\
$\quad$ Posterolateral branch & 41 \\
Diagonal branch & 5 \\
Total & 116 \\
LITA grafts & \\
LAD & 96 (free graft, 2) \\
Diagonal branch & 2 \\
Diagonal branch-LAD (sequential) & 11 \\
Circumflex artery & 4 \\
Total & 113 \\
\hline
\end{tabular}

RITA, Right internal thoracic artery; LITA, left internal thoracic artery; $L A D$, left anterior descending coronary artery.

phrenic branches to its origin. A Jostra retractor (Jostra Medizintechnik GmbH \& Co. KG, Hirrlingen, Germany) was used routinely to facilitate this procedure. After systemic heparinization, the distal branches were clipped and divided and the pedicle was wrapped with papaverinesoaked gauze $(200 \mathrm{mg} / 50 \mathrm{ml}$ of saline solution). Hemostasis of both ITA pedicles was completed before cardiopulmonary bypass was established, all branches being clipped or ligated whether actively bleeding or not. Anteroposterior incisions of the pericardium toward both phrenic nerves at the pleuropericardial reflection were made to provide the shortest route from the ITA origins to the recipient coronary artery while the patient was being cooled (Fig. 1). Just before the ascending aorta was crossclamped, the right ITA pedicle was pulled through the transverse sinus to reconfirm adequacy in length. Myocardial protection was achieved with antegrade cold crystalloid cardioplegia for the first dose, supplemented with topical cooling (cold saline solution) and systemic hypothermia (rectal temperature $32^{\circ} \mathrm{C}$ ). For the second and subsequent doses, intermittent (every 30 minutes) cold potassium-magnesium blood cardioplegic solution was used. The ITA-coronary artery anastomosis was performed with continuous 7-0 polypropylene suture (Prolene; Ethicon) with optical magnification. Hemostasis not only of the anastomosis but also of the pedicle was carefully checked. When conduits necessitating aortic anastomoses were used, both proximal and distal anastomoses were performed during a single period of aortic crossclamping rather than using a side-biting clamp. After resumption of spontaneous beating and when the mean arterial pressure reached 60 to $80 \mathrm{~mm} \mathrm{Hg}$, hemostasis of the right ITA pedicle placed via the transverse sinus was checked for the last time before the patient was weaned from cardiopulmonary bypass.

Postoperative angiography and stress test. Earily postoperative angiography was done 2 to 3 weeks after the operation. The diameters of the native recipient coronary arteries, as well as of the ITAs, were measured in at least two views for determination of the diameter ratios to evaluate size matching. The modified Sheffield test or the Bruce exercise test was also performed before or after the angiograms. 


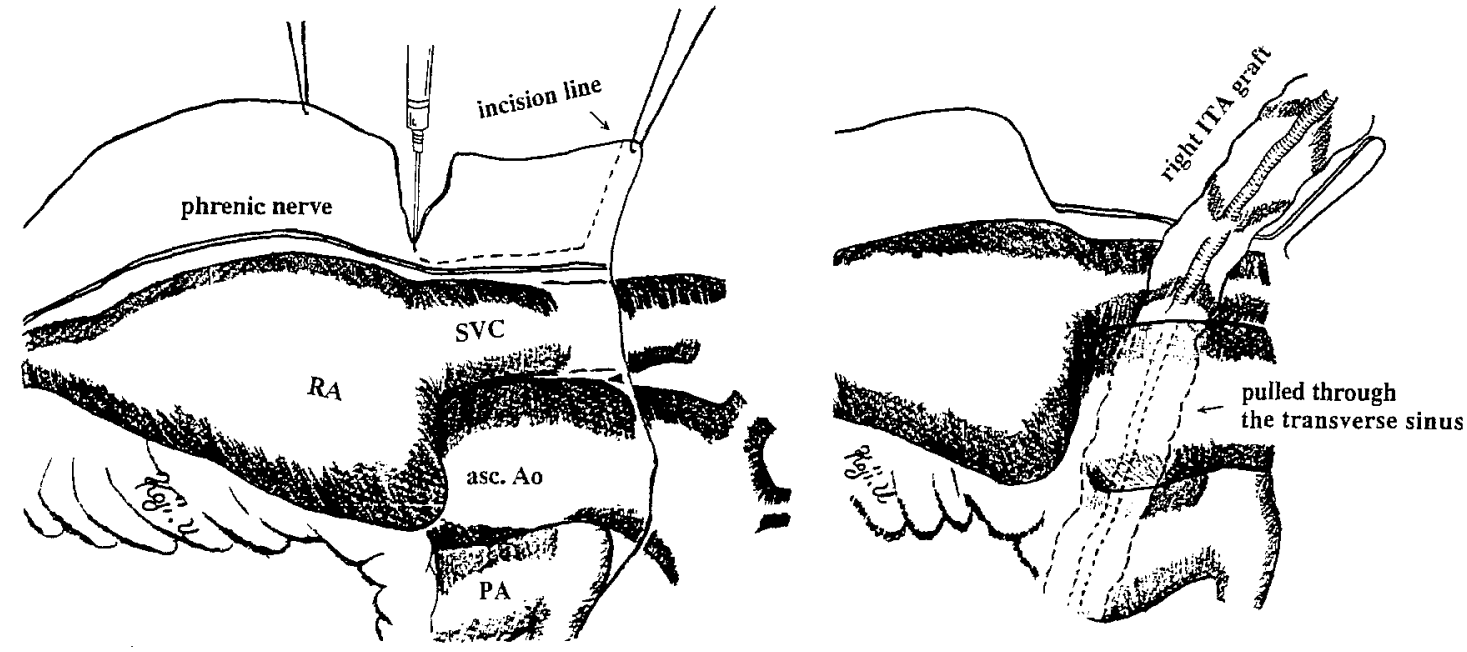

Fig. 1. Right-sided pericardium was incised along the dotted line and right ITA graft (IMA) was pulled through the transverse sinus to graft the target vessel. $S V C$, Superior vena cava; $R A$, right atrium; asc. $A O$, ascending aorta; $P A$, pulmonary artery.

Statistical methods. Data were analyzed by means of the StatView II statistical software package (Abacus Concepts, Inc., Berkeley, Calif.). The $\chi^{2}$ test was used to determine significance for discrete variables and Yates' correction for continuity was applied where applicable. Continuous variables were analyzed by means of Student's $t$ test. Values were expressed as the mean \pm the standard deviation unless otherwise specified. A $p$ value of $<0.05$ was considered significant.

\section{Results}

Mortality. No patient died within 30 days after the operation. The only hospital mortality $(>30$ days) $(0.9 \%)$ occurred in a 69-year-old-woman with a history of bronchial asthma who underwent quadruple $\mathrm{CABG}$ (both ITA grafts and two saphenous vein grafts) who required ventilator support for 5 days. On postoperative day 49 administration of local anesthetic (1\% lidocaine) to repair the left leg wound was followed by a severe asthmatic episode again necessitating ventilator support, which was complicated by pneumonia. She died of septic shock on postoperative day 61 .

Morbidity. Hospital complications are shown in Table IV. Perioperative myocardial infarction, defined as enzyme elevation (creatine kinase MB isozyme concentration $>100$ units) or the appearance of new $\mathrm{Q}$ waves on the electrocardiogram (or both) occurred in 10 patients, four requiring mechanical support (intraaortic balloon pumping): Two needed intraaortic balloon pumping immedi-
Table IV. Hospital complications

\begin{tabular}{lrc}
\hline & No. & $\%$ \\
\hline Perioperative myocardial infarction & 10 & 8.6 \\
Mechanical support (IABP) & 4 & 3.4 \\
Respiratory insufficiency & 5 & 4.3 \\
Reoperation for bleeding & 3 & 2.6 \\
Stroke & 2 & 1.7 \\
Sternal wound complications & 19 & 16 \\
$\quad$ Superficial wound infection & 4 & \\
Skin layer dehiscence & 14 & \\
Sternal fracture from wire cutting & 1 & \\
Bacteriologic mediastinitis & 3 & 2.6 \\
\hline
\end{tabular}

$L A B P$, Intraaortic balloon pump.

ately after cardiopulmonary bypass for ventricular arrhythmia caused by anterior wall ischemia; in the other two patients an inferior wall myocardial infarction developed 10 hours after the operation. No myocardial infarctions were observed after 24 hours, and none of the perioperative myocardial infarctions were in the territory of the right ITA. Respiratory insufficiency, defined as ventilator dependency for more than 48 hours, occurred in five patients. In none was it related to phrenic nerve palsy. Pulmonary embolism occurred in one patient, and one patient with asthma died late, as mentioned. Reexploration for bleeding was necessary in the other three patients, but bleeding points were not related to ITA anastomoses or pedicles. Postoperative stroke was recognized in two patients: 
Table V. Early postoperative angiographic assessment about right ITA grafting

\begin{tabular}{lccc}
\hline & \multicolumn{3}{c}{ Recipient coronary artery } \\
\cline { 2 - 4 } \multicolumn{1}{c}{ Result } & $\begin{array}{c}\text { Marginal } \\
\text { artery }\end{array}$ & $\begin{array}{c}\text { Posterolateral } \\
\text { artery }\end{array}$ & $\begin{array}{c}\text { Diagonal } \\
\text { branch }\end{array}$ \\
\hline Good patent & 68 & 38 & 5 \\
Slow flow & 1 & 1 & - \\
Graft occlusion & - & 1 & - \\
Patency rate & $98.6 \%$ & $95.0 \%$ & $100 \%$ \\
\cline { 2 - 3 } & & & $97.4 \%$ \\
\hline
\end{tabular}

ITA, Internal thoracic artery.

One who awoke with disorientation and monoplegia of the right leg had evidence of a small cerebral infarction in the left basal ganglion, but he was discharged without any sequelae. The other was delirious, complained of hemianopsia, and had evidence of occipital lobe infarction, but his mental state was clear at discharge. Sternal wound problems were observed in 22 patients: Fourteen had skin layer dehiscence but no growth of organisms on culture, four had superficial infections (Staphylococcus epidermidis), and one had a sternal fracture caused by the sternal wire cutting, but negative cultures. Sixteen of them required only local wound care, one patient needed rewiring, and the other two patients healed spontaneously. Mediastinitis (with positive cultures) occurred in three patients, two of whom had diabetes. Two were treated with débridement, open irrigation, and antibiotics, and the other patient was treated with an omental flap. Ten of the 22 patients with wound problems $(45 \%)$ had diabetes. In these 22 patients the mean hospitalization period was lengthened by 8 days.

Postoperative angiography. Early postoperative angiography was performed in 114 patients (98\%) (Table V). Only ITAs with a smooth transition from the graft to the recipient coronary artery without evidence of any stenosis were defined as patent in this series. If the arteriographic flow velocity was poor, even if there was no evidence of stenosis or occlusion, the flow was termed "slow flow" and the graft was not regarded as patent. There was no statistically significant difference among the three groups categorized by anastomotic sites, the overall patency rate of the right ITA graft being $97.4 \%$. The diameter ratios of ITA and recipient coronary artery at the anastomotic site on the postoperative angiogram (as measured with calipers on the screen) were compared between the 69 patients with grafts to the marginal branch and the 37 patients with grafts to the posterolateral branch, and the difference was not statistically significant $(0.94 \pm 0.18$ vs $0.88 \pm$ 0.18 ).

Stress test. A postoperative exercise test was performed in 96 patients $(83 \%)$, and the results were abnormal in only one patient $(1 \%)$, who was free of symptoms. This patient had three vessels bypassed (left ITA to LAD, right ITA to circumflex, vein graft to right coronary artery), and all grafts were angiographically patent. The distal circumflex artery had three branches, every one with $90 \%$ stenosis. The right ITA had been grafted to the largest branch, and it is possible that the two other ungrafted branches were the cause for the abnormal results of the stress test. Except in the patient with the abnormal test results, the average attained maximal exercise was $4.6 \pm 1.4$ metabolic equivalents.

\section{Discussion}

The superiority of ITA grafts over venous conduits has been documented. ${ }^{1-5,20,21}$ Patients receiving a left ITA graft to the anterior wall had improved long-term survival and a reduction in the rate of reoperation and late cardiac events as compared with patients revascularized with saphenous vein. In an effort to expand the use of this superior conduit, different types of ITA grafts were adopted, such as bilateral ITA grafts, sequential bypasses, and free grafts. A number of institutions have reported on the usefulness of bilateral ITA grafts. ${ }^{6-13} \mathrm{We}$ have used this method rather aggressively since 1990. Bilateral ITAs are harvested almost routinely if angiograms suggest that the locations of the coronary lesions are amenable to in situ bilateral ITA grafts and no obvious contraindications exist. Our $97 \%$ patency rate of in situ right ITA grafts, even though early, compares favorably with the $77 \%$ rate for free ITA grafting at 18 months reported by Loop and associates. ${ }^{16}$ We believe that if the ITAs can be used in situ, the results are better than when they are used as free grafts. Our current contraindications for bilateral ITA grafting include the following: patients older than 75 years, female patients in poor physical condition, patients with chronic obstructive pulmonary disease, patients with arteriosclerosis obliterans distal to the iliac artery, and patients with severe diabetes.

The target vessels for ITA anastomoses differ according to the policy of each institution. When we use bilateral ITA grafting for CABG, the anastomo- 
sis pattern left ITA to $\mathrm{LAD}$ and right ITA to circumflex, as described, is generally followed. This strategy is based on two considerations: (1) no necessity to cross the midline anterior to the aorta, thus avoiding risks in case reoperation is required; (2) size matching, that is, the left ITA graft reaches the generally largest coronary artery, the $\mathrm{LAD}$, at a level where is still of good caliber, and the right ITA brought through the transverse sinus matches the circumflex branches.

However, because of the risks of overstretching or rotating the right ITA and the difficulties in managing pedicle bleeding, some reports discredited the original advantages. Rankin and associates ${ }^{14}$ have reported occlusion in two of 20 patients and slow flow in three others. In the report by Ramstorm and colleagues, ${ }^{22}$ the right ITA through the transverse sinus could reach only the most proximal parts of the circumflex artery; consequently the right ITA was predominantly used to revascularize the LAD. In our series the early postoperative patency of the right ITA to circumflex branches was $97.2 \%$, and in only one of 109 cases was it found to be totally occluded. None of our patients required reexploration for pedicle bleeding.

This method of bringing the right ITA via the transverse sinus is indeed more demanding technically; however, the most important aspect is perhaps careful assessment of length before anastomosis and obtaining adequate hemostasis of the pedicle before passing it through the transverse sinus. In our experience we have never changed the target vessel because of length inadequacy, and we have had to use the right ITA as a free graft in only two patients. The ITA pedicle is inspected at least three times for adequate hemostasis. All branches, whether actively bleeding or not, are clipped or ligated.

Thirty-five percent of our right ITA grafts were anastomosed to the distal posterolateral branch. The following are the key points to keep in mind: (1) For maximum length, the pedicle should be harvested after the pleura has been opened; (2) the shortest route to the coronary artery is gained by incising anteroposteriorly the right-sided pericardium anterior to the phrenic nerve at the level of the transverse sinus and then curving the incision cranially alongside the superior vena cava; (3) the distal ITA beyond its bifurcation may have to be used for anastomosis to distal circumflex branches. Although we have not measured flows directly during the operations, the good size matching of the ITA graft to the coronary artery and the normal postoperative exercise test results seem to substantiate the flow adequacy and validity of these points. The postoperative stress test result was abnormal in only one patient (1\%) with residual unbypassed disease, and we believe in all other patients the flows were adequate.

The apparently greater prevalence of sternal wound complications in our study compared with other studies in which bilateral ITA grafts were used $^{23-26}$ lies perhaps in our definition, because we included in our definition wounds that failed to heal primarily regardless of the bacteriologic evidence of infection. When wound complications are limited to culture-positive ones, the overall incidence is $6.1 \%$ $(7 / 116)$ and is similar to that of other reports. Wound complications were more frequent in patients with diabetes. Accordingly, since 1993 the combination of the left ITA and right gastroepiploic artery has been chosen for patients with diabetes requiring insulin or oral hypoglycemic agents, although we have not analyzed the difference.

We conclude that bringing the right ITA via the transverse sinus for grafting the circumflex area provided excellent early patency and good clinical results and should be considered the procedure of choice when revascularization for multivessel disease is undertaken.

We thank A. T. Miyamoto, MD (Kokura Memorial Hospital), for his critical review of the manuscript and for editorial help.

\section{REFERENCES}

1. Singh RN, Sosa JA, Green GE. Long-term fate of the internal mammary artery and saphenous vein grafts. J Thorac Cardiovasc Surg 1983;86:359-63.

2. Grondin CM, Campeau L, Lesperance J, Enjalbert M, Bourassa MG. Comparison of late changes in internal mammary artery and saphenous vein grafts in two consecutive series of patients 10 years after operation. Circulation 1984; 70(Suppl):I208-12.

3. Lytle BW, Loop FD, Cosgrove DM, Ratliff NB, Easley K, Taylor PC. Long-term (5 to 12 years) serial studies of internal mammary artery and saphenous vein coronary bypass grafts. J Thorac Cardiovasc Surg 1985;89:248-58.

4. Loop FD, Lytle BW, Cosgrove DM, et al. Influence of the internal mammary artery graft on 10-year survival and other cardiac events. N Engl J Med 1986;314:1-6.

5. Ivert T, Nuttunen K, Landou C, Björk VO. Angiographic studies of internal mammary artery grafts 11 years after coronary artery bypass grafting. J Thorac Cardiovasc Surg 1988;96:1-12.

6. Lytle BW, Cosgrove DM, Saltus GL, Taylor PC, Loop FD. Multivessel coronary revascularization without saphenous vein: long-term results of bilateral internal mammary bypass grafting. Ann Thorac Surg 1983;36:540-7.

7. Huddlestone CB, Stoney WS, Alford WC Jr, et al. Bilateral 
internal mammary artery grafts: technical factors influencing patency. Ann Thorac Surg 1986;42:543-9.

8. Galbut DL, Traad EA, Dorman MJ, et al. Bilateral internal mammary artery grafts in reoperative and primary coronary bypass surgery. Ann Thorac Surg 1991;52:20-8.

9. Fiore AC, Naunheim KS, McBride LR, et al. Fifteen-year follow-up for double internal thoracic artery grafts. Eur J Cardiothorac Surg 1991;5:248-52.

10. Dion R, Etienne P, Verhelst R, et al. Bilateral mammary grafting: clinical, functional and angiographic assessment in 400 consecutive patients. Eur J Cardiothorac Surg 1993;7:287-94.

11. Green GE, Swistel DG, Cameron AA. Bilateral internal thoracic artery surgery: 17-year experience. Eur Heart J 1989;10(Suppl H):57-60.

12. Fiore AC, Naunheim KS, Dean $P$, et al. Results of internal thoracic artery grafting over 15 years: single versus double grafts. Ann Thorac Surg 1990;49:202-9.

13. Naunheim KS, Barner HB, Fiore AC. 1992 update. Ann Thorac Surg 1992;53:716-8.

14. Rankin JS, Newman GE, Bashore TM, Muhlbaier LH, Tyson GS Jr, Ferguson TB Jr, et al. Clinical and angiographic assessment of complex mammary artery bypass grafting. $\mathrm{J}$ Thorac Cardiovasc Surg 1986;92:832-46.

15. Tector AJ, Schmachl TM, Canino VR. Expanding the use of the internal mammary artery to improve patency in coronary artery bypass grafting. J Thorac Cardiovasc Surg 1986;91:9-16.

16. Loop FD, Lytle BW, Cosgrove DM, Golding LAR, Taylor PC, Stewart RW. Free (aorta-coronary) internal mammary artery graft. J Thorac Cardiovasc Surg 1986;92:827-31.

17. McBride LR, Barner HB. The left internal mammary artery as a sequential graft to the left anterior descending system. $J$ Thorac Cardiovase Surg 1983;86:703-5.
18. Tector AJ, Schmahl TM, Kallies JR, Sanfillippo D. The role of the sequential internal mammary artery graft in coronary surgery. Circulation 1984;70(Suppl):I222-5.

19. Puig LB, Neto LF, Rati M, et al. A technique of anastomosis of right internal mammary artery to the circumflex artery and its branches. Ann Thorac Surg 1984;38:533-4.

20. Speiser K, Rothlin M, Turina M. Comparison between internal mammary artery implantation and aorto-coronary vein bypass grafting in coronary artery disease with significant left anterior descending stenosis. J Cardiovasc Surg 1983;31: 54.

21. Tector AJ, Schmal TM, Canino VR. The internal mammary artery graft: the best choice for bypass of the diseased left anterior descending coronary artery. Circulation 1983; 68(Suppl):II214.

22. Ramstorm J, Lund O, Cadavid E, Oxelbark S, Thuren JB, Henze AC. Right internal mammary artery for myocardial revascularization: early results and indications. Ann Thorac Surg 1993;55:1485-91.

23. Kouchoukos NT, Wareing TH, Murphy SF, Pelate C, Marshall WG Jr. Risks of bilateral interanal mammary artery bypass grafting. Ann Thorac Surg 1990;49:210-9.

24. Loop FD. Expanded use of internal thoracic artery. Curr Opin Cardiol 1989;4:785-8.

25. Loop FD, Lytle BW, Cosgrove DM, et al. Sternal wound complications after isolated coronary artery bypass grafting: early and late mortality, morbidity, and cost of care. Ann Thorac Surg 1990;49:179-87.

26. Grossi EA, Esposito R, Harris LJ, Crooke GA, Galloway AC, Colvin SB, et al. Sternal wound infections and use of internal mammary artery grafts. J Thorac Cardiovasc Surg 1991;102: 342-7. 